\title{
Prognostic impact of circulating Her-2-reactive T-cells producing pro- and/or anti-inflammatory cytokines in elderly breast cancer patients
}

\author{
Jithendra Kini Bailur ${ }^{1,5^{*}}$, Evelyna Derhovanessian ${ }^{1,3}$, Brigitte Gueckel ${ }^{2}$ and Graham Pawelec ${ }^{1,4}$
}

\begin{abstract}
Background: Treating elderly breast cancer patients remains a challenge but the increasing availability of immunotherapeutic approaches instills optimism that these tumours may also be susceptible to immune control. Because aging leads to a number of alterations in the immune system ("immunosenescence") reflecting potential exhaustion which could compromise immunomodulatory antibody therapy, here we have assessed the immunocompetence of elderly breast cancer patients compared with a group of younger patients, and related this to the 5 -year survival of the former.

Methods: T-cell responses to Her-2 peptide pools in vitro were assessed by analyzing pro- and anti-inflammatory cytokine production by CD4+ and CD8+ T-cells in 40 elderly and 35 younger breast cancer patients.

Results: The proportions of older and younger patients whose peripheral T-cells responded to Her-2 peptides in vitro were found to be similar, although a significantly higher fraction of younger patients possessed IL-2-producing CD4+ Her-2-reactive T-cells than in the elderly $(p=0.03)$. However, IL-2 production did not impart a survival benefit to the latter. In contrast, there was a survival benefit of possessing Her-2-reactive CD8+ T-cells, but this was abrogated in patients if they also had CD4+ Her-2-responsive T-cells that producedIL-5 and/or IL-17 ( $p=0.01)$. This resulted in a 5-yr survival rate of only $29 \%$ compared to $76 \%$ for patients whose her-2-reactive CD4+ T-cells did not producell-5 and/or IL-17. Additionally, patients whose CD8+ T-cells produced TNF had a significantly better survival than those that did not (93\% compared to $52 \%, p=0.01$ ), whereas no survival benefit was attributable to possessing IFN- $\gamma$-producing cells.

Conclusions: Elderly breast cancer patients appear perfectly immunocompetent to respond to Her-2 peptide pools in vitro, with response patterns very similar to younger patients. The nature of this response is associated with 5-year survival of these elderly patients, suggesting that boosting anti-tumor responses and modulating the nature of the T-cell response is likely to be effective even in potentially immunosenescent elderly breast cancer patients, and might be useful for predicting which patients are most likely to benefit from such treatments.
\end{abstract}

Keywords: T-cells, Breast cancer, Her-2, Elderly, Tumour-associated antigens, Cytokines, Immunosenescence

\section{Background}

The prevalence of most types of cancer increases with age. One reason for this may be that aging is associated with dysregulated immunity, which could contribute to increased susceptibility to infections and cancer [1]. Treating elderly breast cancer patients remains a major

\footnotetext{
* Correspondence: jithendra.kini@gmail.com

'Department of Internal Medicine II, Centre for Medical Research, University

of Tuebingen, Waldhoernlestr 22, 72072 Tuebingen, Germany

${ }^{5}$ Present Address: Yale Cancer Center, Yale University School of Medicine,

New Haven, CT, USA

Full list of author information is available at the end of the article
}

challenge. The elderly are underrepresented in clinical trials, of which there are hardly any that have specifically considered elderly cohorts. Generally, the same treatment regimens are applied to both younger and older cancer patients, but the latter are not able to tolerate chemotherapy or radiotherapy to the same extent and may thus be under-treated $[2,3]$. Although there are many suggestions as to how to treat elderly breast cancer patients [4-6], and considering the recent breakthroughs in immunotherapy of melanoma and other cancer types, more investigations need to be conducted to understand the immune system 
of these patients and the potential role of ageing and immunosenescence in treatment outcome. The hallmarks of immunosenescence may be observed chronologically earlier in chronic viral infections and cancer [7, 8]. There is a number of alterations that are known to occur with aging $[9,10]$, which include changes in the number and distribution of $\mathrm{T}$ and $\mathrm{B}$ lymphocytes and their differentiation states $[8,11]$. As T-cells play a crucial role in adaptive immunity, their efficient activation to defend against cancer or viral infection is important. Dendritic cells (DCs) are necessary for activating the T-cells efficiently. Aging may also result in alterations of important co-receptors on DCs that could result in weakened T-cell response, possibly reducing anti-cancer immunity $[12,13]$. Generally, higher levels of serum inflammatory markers are also observed in the elderly, which could play a role in the activation of immunosuppressive cell subsets making it more difficult to resist cancer $[14,15]$. Thus, there are several loci at which immunosenescence could interfere with anti-cancer immunity and accordingly compromise immunotherapies. The recent striking clinical success of employing immunomodulatory antibodies such as anti-CTLA-4, PD-1 or PDL1which "take the brakes off" immunity and are showing extremely promising results in some cancers in a proportion of treated patients makes it even more important to determine the effect of age on the immune status of cancer patients [16-18]. Such therapies are likely to be effective only when the patient remains capable of mounting an anti-cancer immune response. In elderly patients, immunosenescence could compromise these responses.

Earlier, we showed that the presence of peripheral T-cells responding to certain tumor-associated antigens (TAA) in stage IV melanoma was associated with longer survival and that the pro- or anti-inflammatory nature of the $\mathrm{T}$ cell response influenced the strength of this association $[19,20]$. Thus, T-cell responsiveness to TAA is an important prognostic biomarker of survival. Melanoma patients tend to be relatively young compared to most other solid cancer patients, and so we asked whether this type of biomarker reflecting T-cell functional integrity would also be informative in older patients. We therefore elected to examine this issue in a cohort of some of the oldest such patients, namely in elderly female breast cancer patients. We had previously reported that elderly patients with in vitro CD8+ T-cell responses against pooled Her-2 peptides survived longer than those who did not [21], suggesting that immunosenescence had not compromised responsiveness and that immunomodulatory therapies should also be effective in these patients. Here, we compared the immunocompetence of these elderly patients with a group of younger patients and found that they were indeed similar in this respect. We have continued these first studies on the elderly to dissect the nature of their CD4+ and CD8+ Tcell responses to Her-2 peptides in relation to their overall survival, where we were able to show the association of certain pro- and anti-inflammatory cytokines produced by CD4+ and CD8+ T-cells with overall survival, analogous to similar findings in melanoma [20].

\section{Results}

T-cell responses to Her-2

A majority of the elderly $(97 \%, n=38)$ and all younger $(100 \%, n=35)$ breast cancer patients analyzed had in vitro $\mathrm{T}$ cell responses to mixtures of Her- 2 peptides. FACS plots from a representative donor are shown in Additional file 1: Table S2. CD4+ T-cell responses to Her-2 were observed in most individuals in the case of both older $(32 / 38,87 \%)$ and younger $(33 / 35,94 \%)$ patients, whereas only 18 of the former $(47 \%)$ and 21 of the latter $(60 \%)$ possessed CD8+ T-cells responding to Her-2 peptides. ThisCD8+ T-cell response was present irrespective of whether the patients also had a CD4+ T-cell response to Her-2. Taking advantage of our ability to analyze 6 different cytokines simultaneously by intra-cellular staining of individual T-cells by flow cytometry, we grouped the Her- 2 responders according to the cytokines produced by their CD4+ and CD8+ T-cells.

\section{CD8+ T-cell responses to Her-2}

As described above, a CD8+ T-cell response to Her-2, defined as the production of any one of the 6 tested cytokines, was observed in 18/38 (47 \%) older and 21/35 (60\%) younger patients. In a high proportion of these patients, CD8+ T-cells responding to Her-2produced the pro-inflammatory cytokines TNF $(14 / 18,78 \%$ in old; $16 / 21,76 \%$ in young) and IFN- $\gamma(13 / 18,72 \%$ in old; $18 / 21,86 \%$ in young). Only a small proportion of CD8+ T-cells produced IL-2 and IL-10 in either old or young patients (Tables 1 and 2).

\section{CD4+ T-cell responses to Her-2}

Analyzing the nature of the CD4+ T-cell responses to Her2 peptides, we observed that these cells mainly produced the pro-inflammatory cytokines TNF $(27 / 32,84 \%$ in old; $27 / 33,82 \%$ in young), IFN- $\gamma$ (23/32, $72 \%$ in old; $28 / 33$, $85 \%$ in young) and, unlike for CD8+ T-cells, also IL-2 (13/ $32,41 \%$ in old; $22 / 33,67 \%$ in young). The higher fraction of younger relative to older patients whose CD4+ T-cells produced IL-2 in response to Her-2 was statistically significantly different $(p=0.03)$. As for CD8+ T-cell responses, IL10, IL- 5 and IL-17 were rarely produced by either young or old patients (Tables 1 and 2).

\section{The T-cell response to Her-2 correlates with overall survival}

Previously, we had shown that elderly patients who had a CD8+ T-cell response to Her-2 had a survival advantage over those who $\operatorname{did} \operatorname{not}(p=0.03)$. The overall (5-year) survival rate was $52 \%$ for patients without a CD8+ T-cell 
Table 1 Cytokines produced by Her-2 responders in old breast cancer patients

\begin{tabular}{|c|c|c|c|c|c|}
\hline \multicolumn{6}{|l|}{ Old $(n=38)$} \\
\hline CD4 & Response & No. of patients & $\%$ Dead & 5-year survival rate & $P$ value \\
\hline \multirow[t]{2}{*}{ TNF } & Yes & 27 & 37 & 60 & 0.1 \\
\hline & No & 11 & 18 & 81 & \\
\hline \multirow[t]{2}{*}{ IFN- $\gamma$} & Yes & 23 & 43 & 57 & 0.1 \\
\hline & No & 15 & 13 & 84 & \\
\hline \multirow[t]{2}{*}{ IL-5 } & Yes & 7 & 57 & 43 & 0.1 \\
\hline & No & 31 & 23 & 73 & \\
\hline \multirow[t]{2}{*}{ IL-10 } & Yes & 3 & 33 & 67 & 0.8 \\
\hline & No & 35 & 31 & 65 & \\
\hline \multirow[t]{2}{*}{ IL-2 } & Yes & 13 & 46 & 54 & 0.3 \\
\hline & No & 25 & 24 & 74 & \\
\hline \multirow[t]{2}{*}{ IL-17 } & Yes & 3 & 67 & 33 & 0.3 \\
\hline & No & 35 & 29 & 70 & \\
\hline \multirow[t]{2}{*}{ IL-5 and or IL-17 } & Yes & 10 & 50 & 29 & 0.01 \\
\hline & No & 28 & 25 & 76 & \\
\hline \multicolumn{6}{|l|}{ CD8 } \\
\hline \multirow[t]{2}{*}{ TNF } & Yes & 14 & 7 & 93 & 0.01 \\
\hline & No & 24 & 46 & 52 & \\
\hline \multirow[t]{2}{*}{ IFN- $\gamma$} & Yes & 13 & 23 & 76 & 0.3 \\
\hline & No & 25 & 36 & 62 & \\
\hline \multirow[t]{2}{*}{ IL-10 } & Yes & 2 & 50 & 50 & 0.7 \\
\hline & No & 36 & 31 & 68 & \\
\hline \multirow[t]{2}{*}{ IL-2 } & Yes & 1 & 0 & 100 & 0.5 \\
\hline & No & 37 & 32 & 66 & \\
\hline
\end{tabular}

Results of survival analysis according to Kaplan Meier method and $p$ values from Mantel-Cox (log-rank) test

response to Her-2, compared with $82 \%$ for those had a CD8+ T-cell response. There was only $17 \%$ mortality in the group of patients with a CD8+ T-cell response to Her-2 whereas this was $45 \%$ for patients without a CD8+ T-cell response. In the present study, we stratified patients according to whether they had only a CD8+ T-cell response, only a CD4+ T-cell response or both CD4+ and CD8+ Tcell responses to Her-2 peptides, and performed a KaplanMeier analysis (Table 3). We confirmed a survival benefit for patients with Her-2-reactive CD8+ T-cells as observed in our earlier study, but there was no survival advantage for patients with a CD4+ T-cell response to Her-2. Moreover, those patients with a CD8+ T-cell response to Her-2 who also had a CD4+ T-cell response had poorer survival than those with only a CD8+ T-cell response. A significant early negative impact on survival can also be observed for patients with no CD8+ T-cell response to Her-2 (Gehan Breslow test: $p=0.02$ ) (Fig. 1). The 5-year survival rate for patients with a solely CD4+ T-cell response was $49 \%$ compared to $77 \%$ and $100 \%$ for those with combined CD4+ and CD8+ T-cell responses or only a CD8+ T-cell response, respectively. Survival analyses were not possible in the younger patients because only two had died. Nonetheless, these two had both CD4+ and CD8+ T-cell responses to Her-2.

\section{Impact of the presence of CD4+ T-cells producing IL-5 and IL-17 on survival}

Patients were stratified according to the cytokines produced by their $\mathrm{CD} 4+$ or $\mathrm{CD} 8+\mathrm{T}$-cells. Considering the elderly breast cancer patients, Kaplan-Meier survival analysis showed that patients whose CD4+ T-cells produced IL-5 tended to have poorer outcomes $(p=0.1$, Fig. 2a) with a survival rate of $43 \%$ compared to $73 \%$ for patients whose CD4+ T-cells did not produce IL-5 when stimulated with Her-2 peptides. A weaker trend towards a similar impact on survival was observed for patients whose CD4+ T-cells produced IL-17 ( $p=0.3$, Fig. $2 \mathrm{~b}$ ). Here, those whose CD4+ T-cells produced IL-17 had a $33 \% 5$-year survival compared to $70 \%$ for those who did not produce IL-17. Despite the lack of statistical significance when considering IL 5 and IL 17 production separately, when we analyzed patients whose CD4+ T-cells produced IL-5 and/or IL-17, we did observe a significant impact on the overall survival 
Table 2 Cytokines produced by Her-2 responders in young breast cancer patients

\begin{tabular}{|c|c|c|c|c|}
\hline \multicolumn{5}{|l|}{ Young $(n=35)$} \\
\hline $\mathrm{CD} 4$ & Response & No. of patients & \% Dead & $P$ value \\
\hline \multirow[t]{2}{*}{ TNF } & Yes & 27 & 7 & 0.5 \\
\hline & No & 8 & 0 & \\
\hline \multirow[t]{2}{*}{ IFN- $\gamma$} & Yes & 28 & 7 & 0.6 \\
\hline & No & 7 & 0 & \\
\hline \multirow[t]{2}{*}{ IL-5 } & Yes & 8 & 25 & 0.04 \\
\hline & No & 27 & 0 & \\
\hline \multirow[t]{2}{*}{ IL-10 } & Yes & 4 & 0 & 0.7 \\
\hline & No & 31 & 6 & \\
\hline \multirow[t]{2}{*}{ IL-2 } & Yes & 22 & 9 & 0.4 \\
\hline & No & 13 & 0 & \\
\hline \multirow[t]{2}{*}{ |L-17 } & Yes & 6 & 17 & 0.6 \\
\hline & No & 29 & 3 & \\
\hline \multirow[t]{2}{*}{ IL-5 and or IL-17 } & Yes & 12 & 17 & 0.1 \\
\hline & No & 23 & 0 & \\
\hline \multicolumn{5}{|l|}{ CD8 } \\
\hline \multirow[t]{2}{*}{ TNF } & Yes & 16 & 13 & 0.3 \\
\hline & No & 19 & 0 & \\
\hline \multirow[t]{2}{*}{ IFN- $\gamma$} & Yes & 18 & 11 & 0.3 \\
\hline & No & 17 & 0 & \\
\hline \multirow[t]{2}{*}{ IL-10 } & Yes & 2 & 0 & 0.3 \\
\hline & No & 33 & 6 & \\
\hline \multirow[t]{2}{*}{ IL-2 } & Yes & 2 & 0 & 0.8 \\
\hline & No & 33 & 6 & \\
\hline
\end{tabular}

Results of survival analysis according to Kaplan Meier method and $p$ values from Mantel-Cox (log-rank) test

( $p=0.01$, Fig. 3a) in these elderly breast cancer patients. Thus, the survival rate for patients whose CD4+ T-cells produced IL-5 and/or IL-17 was $29 \%$ compared to $76 \%$ for the patients without these cytokines. From the KaplanMeier analysis of different parameters in the elderly we observed the expected impact of metastasis on survival (Additional file 2: Table S1). Limiting the analysis to nonmetastatic elderly breast cancer patients only, we still observed a similar negative impact on survival for the

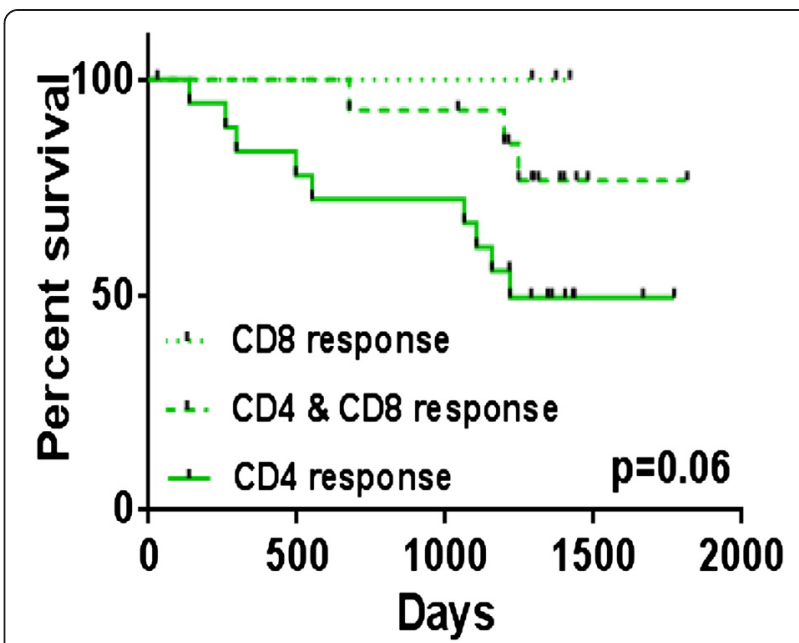

Fig. 1 Survival analysis of elderly breast cancer patients according to CD8+ T-cell responses to Her-2peptides in vitro. Survival analysis of elderly patients $(n=38)$ grouped according to CD8+ T-cell responses to Her-2 (CD8 response), CD4+ and CD8+ T-cell responses (CD4 \& CD8response) and CD4+ T-cell responses to Her-2 (CD4 response)

patients whose CD4+ T-cells produced IL-5 and/or IL-17 $(p=0.02$, Fig. $3 \mathrm{~b})$. Here, the survival rate was only $33 \%$ compared to $80 \%$ for patients whose CD4+ T-cells did not produce these cytokines.

Analogous observations were also made anecdotally in the younger patients, where those whose CD4+ T-cells produced IL-5 had poor survival, with $25 \%(2 / 8)$ of the IL-5-producing patients dying, compared to none whose CD4+ T-cells did not produce IL-5.

\section{Impact of TNF-producing CD8+ T-cells on survival}

We previously reported the beneficial effects of having a CD8+ T-cell response to Her-2. Here, we investigated the function of these Her-2 specific CD8+ T-cells to identify the factors associating with survival benefit in this cohort. We observed that patients whose CD8+ T-cell produced TNF had a significantly better survival than those whose CD8+ T-cells did not produce TNF, when all elderly patients were included in the analysis $(p=0.01$, Fig. 4a). The survival rate for the patients whose CD8+ T-cells produced TNF was $93 \%$ compared to $52 \%$, for those with no

Table 3 Phenotype of Her-2 responders in older patients

\begin{tabular}{lllll}
\hline Response to Her-2 & & No. of patients & Percentage dead & $p$ value \\
\hline CD4 response & Yes & 33 & $36 \%$ & $0 \%$ \\
No & 4 & $13 \%$ & 0.1 \\
CD response & Yes & 18 & $47 \%$ & 0.03 \\
CD4 and CD8 response & No & 19 & $21 \%$ & 0.2 \\
& Yes & 14 & $39 \%$ & 0 \\
\hline
\end{tabular}




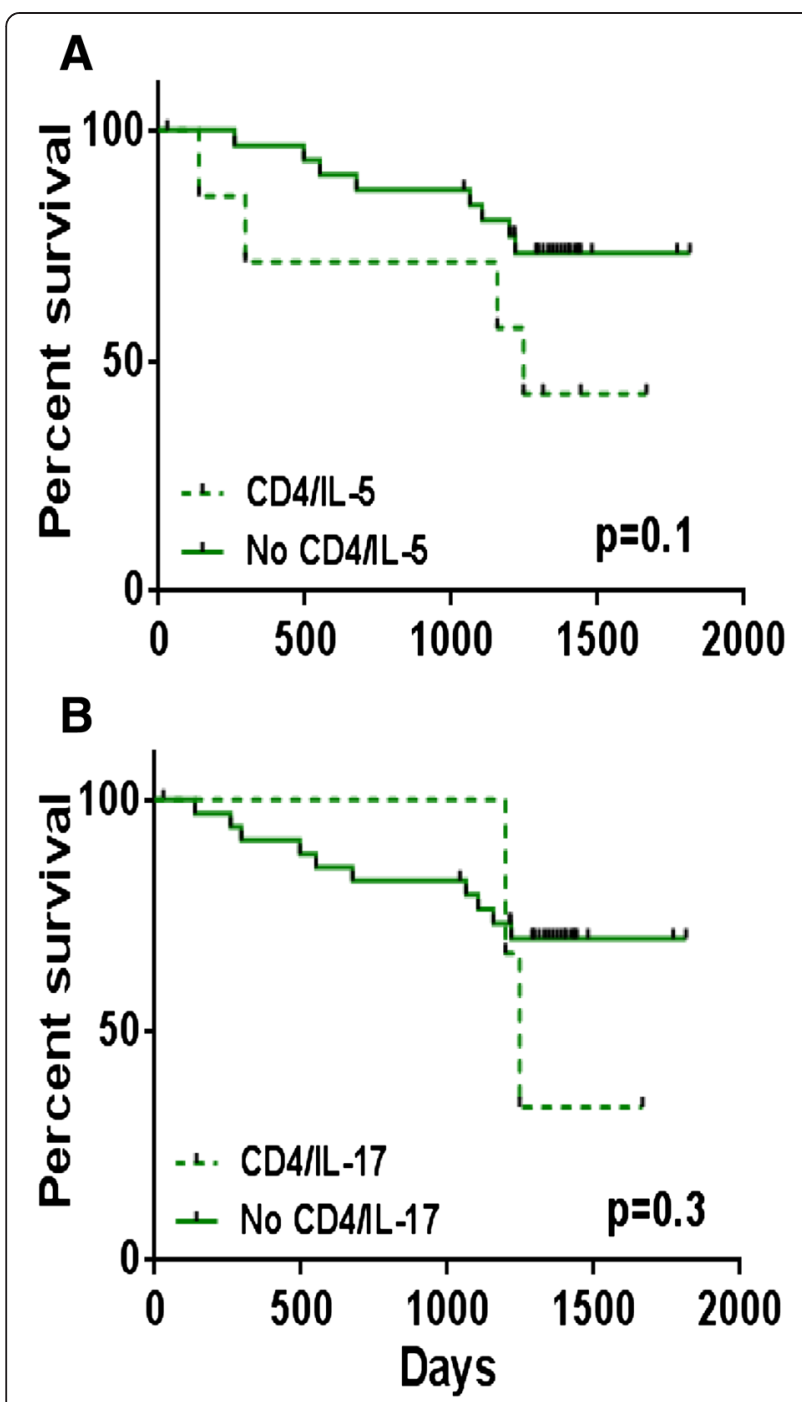

Fig. 2 Survival analysis of elderly breast cancer patients according to IL-5 or IL-17 production by Her-2-stimulated CD4+ T-cells. a Patients grouped according to IL-5 production; $\mathbf{b}$ IL-17 production
TNF-producing CD8+ T-cells. This survival advantage was still observed when only non-metastatic elderly patients were considered ( $p=0.05$, Fig. $4 \mathrm{~b})$. In the case of nonmetastatic patients, these figures were $92 \%$ and $57 \%$, respectively. No survival associations could be observed in young.

\section{Impact of IFN- $\gamma$ producing CD8+ T-cell on survival}

Here, we grouped the patients according to CD8+ Tcell production of IFN- $\gamma$. Unlike the findings with TNF above, unexpectedly, Kaplan-Meier survival analysis indicated no significant differences between IFNproducers and non-producers both in young and old $(p=0.3$, Fig. $4 c)$.

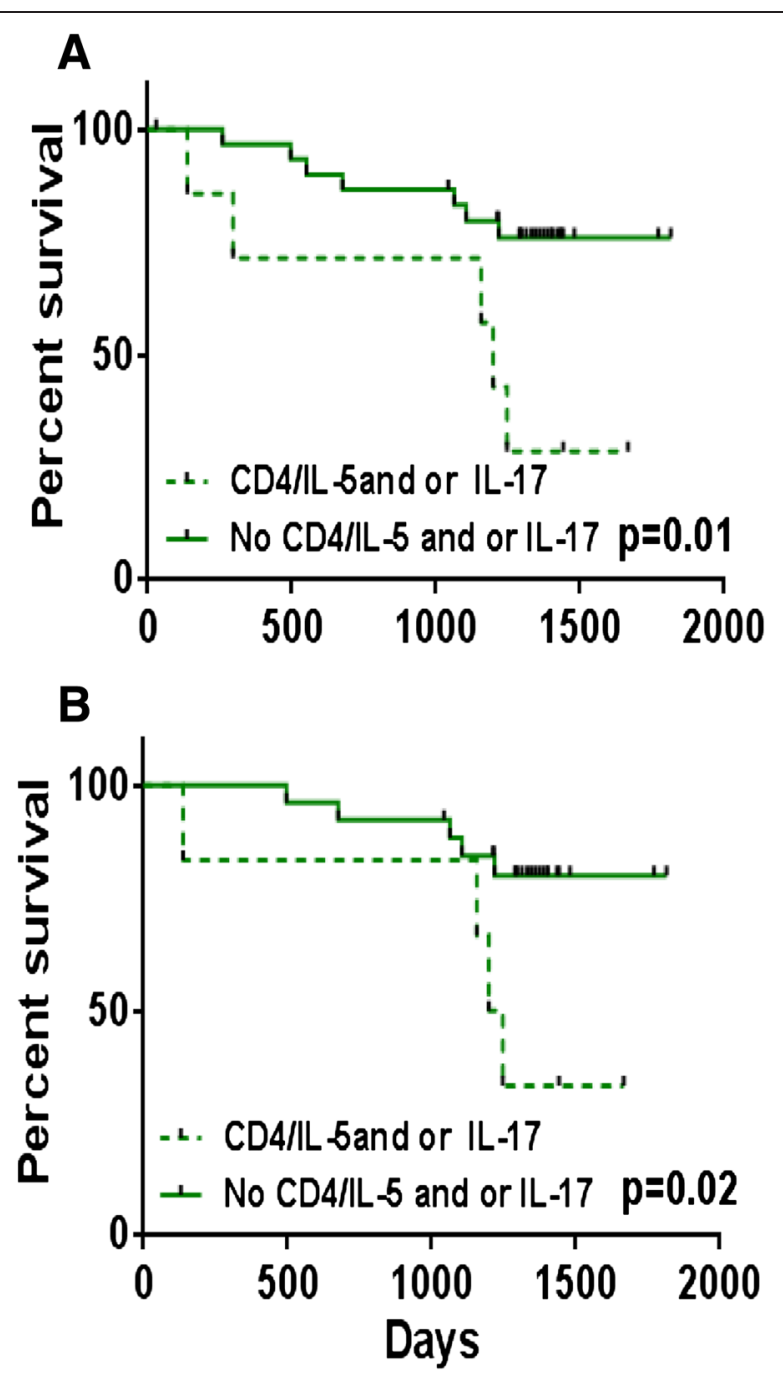

Fig. 3 Survival analysis of elderly breast cancer patients according to IL-5 and/or IL-17 production by Her-2-stimulated CD4+ T-cells. a patients grouped according to $\mathrm{IL}-5$ and/or $\mathrm{IL}-17$ production in all patients and $\mathbf{b}$ in non-metastatic patients only

\section{Discussion}

In the present study, we investigated associations of the presence of circulating Her-2-reactive CD4+ and CD8+ Tcells with survival in older breast cancer patients relative to their pro- and anti-inflammatory cytokine production on stimulation, and compared the immunocompetence of the elderly, as assessed in this manner, with that of younger patients. Previously, we had reported a survival benefit accruing to patients having a CD8+ T-cell response to Her-2 [21]. To test the hypothesis that the immune system in the elderly may be compromised due to aging, here we investigated differences in T-cell responses to Her-2 in younger and older breast cancer patients. To the best of our knowledge, this is the first study to investigate the phenotype and function of Her- 2 reactive T-cells, or those reactive to 


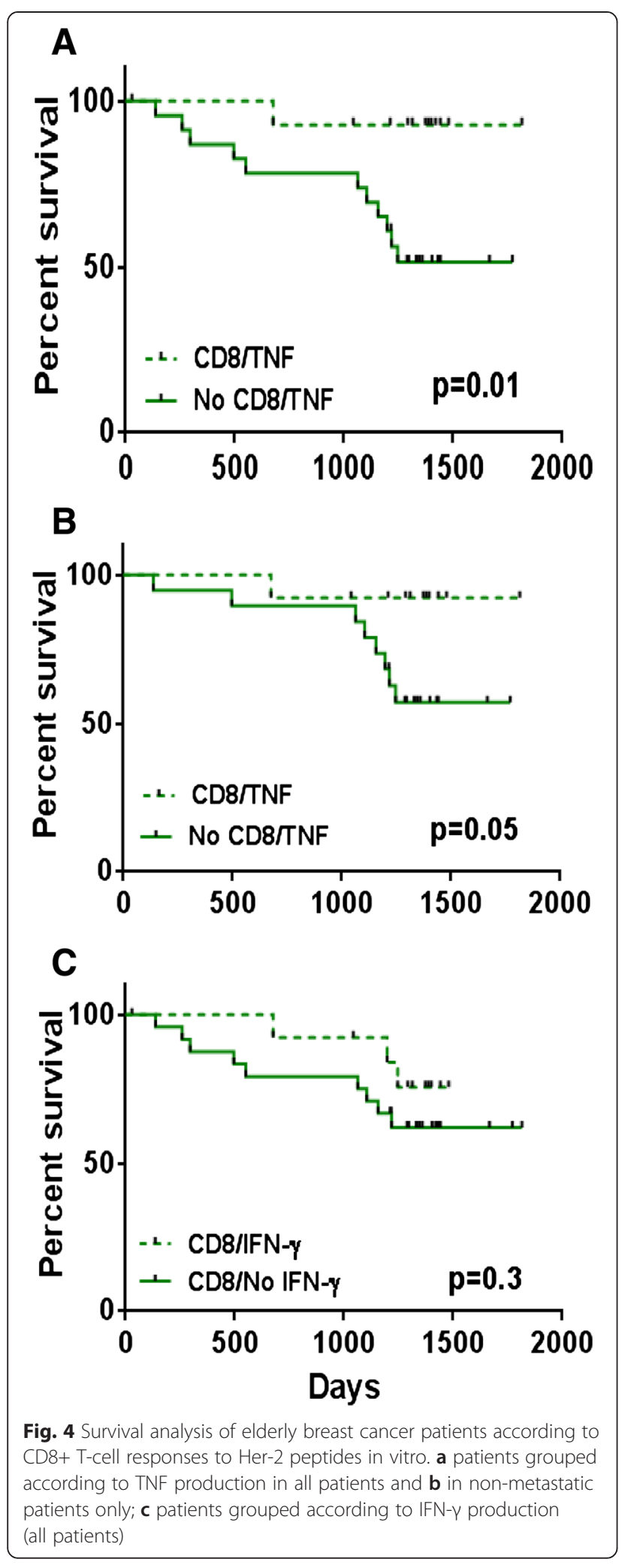

any tumor-associated antigen, in young and old breast cancer patients.

In the present study, stratifying the patients according to those having a CD8+ T-cell response alone (positive impact on survival as previously shown), or both CD4+ and CD8+ $\mathrm{T}$-cell responses, or only a CD4+ T-cell response revealed a trend towards a negative general survival impact for CD4+ $\mathrm{T}$-cell reactivity in older patients. These results clearly confirmed the importance of having a CD8+ T-cell response to Her-2 but also showed that there was reduced survival when a CD4+ T-cell response to Her-2 was also present in the same patient. This implies that at least in terms of responses to Her-2, CD4+ T-cell reactivity to this TAA is likely to have unanticipated negative effects. CD4+ regulatory $\mathrm{T}$ cells would be the obvious candidates for the cells mediating these negative effects. The lack of CD8+ T-cell responses in patients with poorer survival could also be due to the presence of increased levels of Tregs. This would be consistent with other reported studies showing that Tregs could control the T-cell response against certain TAAs in an antigen-specific manner [22, 23]. We were not able to test for classic Treg phenotypes in the current study due to the limitations of the flow cytometric technique, but will focus on this question in future studies. We can only say at this juncture that one cytokine commonly implicated in Treg function, IL-10, does not seem to be responsible for these results, whereas two other cytokines not generally implicated in Treg function, namely IL-5 and IL-17, do seem to play important roles. Thus, functional analysis of 6 different cytokines allowed us to group patients according to the cytokines produced by the CD4+ and CD8+ T-cells responding to Her-2. Survival analysis showed that the presence of CD4+ T-cells producing IL-5 and/or IL-17 had a negative impact on survival in the elderly $(p=0.01)$. Compared to other anti-inflammatory cytokines, the role of IL-5 in peripheral cells seems to be under-investigated. Studies have indicated that IL-5 may facilitate lung metastasis, and high expression of IL-5 in the tumor was also negatively associated with survival $[24,25]$. A potential role in immune surveillance has been proposed [26]. Similarly, there are few data on IL-17 in this context. Although IL-17 is primarily considered a pro-inflammatory cytokine, its role in cancer is still unclear. Some studies have shown antitumor effects of IL-17, so that it has been proposed for use as a cancer immunotherapeutic $[27,28]$. However, tumorinfiltrating lymphocytes with a high level of IL-17-positivity correlate with poor prognosis in some studies [29, 24], and an association of IL-17 with Tregs in the tumor has been reported [29]. We also need to bear in mind that not only Tregs, but also myeloid-derived suppressor cells (MDSCs) may play a role in suppressing T-cell activity. We previously reported the possible suppressive role of MDSCs and Tregs in relation to T-cell responses to Her- 2 and also the possible indirect role of these immunosuppressive subsets in 
breast cancer [21]. MDSCs are also associated with IL-17, as they are able to mediate IL-17 production by naïve Tcells, depending on the cytokines produced by the MDSCs themselves [30]. Consistent with the present report, our previous study investigating the role of IL-17 in the context of CD4+ T-cell responses to TAAs documented a negative impact oflL-17-producing T-cells in late-stage melanoma [20]. There are several other cytokines such as IL-4 and IL13 that are known to have a negative impact on survival $[31,32]$ and which would have been interesting to examine here, especially as we previously found that IL 4 was relevant in melanoma. IL-13 is known to regulate cancer invasion and metastasis in different cancers [31, 32]. In our previous study on melanoma, we observed a negative impact on survival for the patients who produced IL-4 reactive to Melan-A [20]. IL-4 is also known to trigger the cancer proliferation mechanism [33]. Not only these but also IL-6 and IL-1 have shown a negative impact on survival and tumor progression $[34,35]$. However, the number of different variables that could be tested at the same time was limited and we were unable to include these other cytokines in the present analysis.

The role of the pro-inflammatory cytokines IL-2, IFN- $\gamma$ and TNF in cancer is usually considered to be wellestablished. They play an important role in inducing a protective immune response [36] and IL-2 has long been used as an immunotherapeutic drug which can result in a small minority of very durable responses [37]. In the present study, one of the few differences that we observed between younger and older patients was that significantly lower proportion of the latter possessed Her-2-reactive IL-2 producing CD4+ T-cells, possibly contributing to better survival of the former. However, whether or not an elderly patient possessed IL-2-producing CD4+ T-cells had no impact on survival.

IFN- $\gamma$ is known to play an important role in anti-tumor activity [38, 39] and has also been considered as an immunotherapeutic drug to treat cancer patients [40, 41]. In our study, however, we could discern no significant survival advantage for patients with Her-2-reactive CD8+ T-cells producing IFN- $\gamma$, although there was a survival advantage for patients who had Her-2-reactive TNF-producing CD8+ T-cells. TNF is involved in a number of important cellular functions including cell proliferation, survival and death and has been used in patients with locally advanced tumors [42]. In the present study, we observed that patients whose CD8+ T-cells produced TNF had a significant survival advantage over those who did not, indicating the importance of Her-2-reactive TNF-producing CD8+ T-cells for these elderly breast cancer patients.

\section{Conclusions}

From our results, we propose that the nature of the antitumor T-cell response and the TAA targeted by T-cells present in the circulation is important and has an impact on patient survival. Considering the results presented in this study, depletion of Her-2-specific IL-5- and IL-17producing CD4+ T-cells and enrichment of TNFproducing $\mathrm{CD} 8+\mathrm{T}$-cells for adoptive $\mathrm{T}$-cell therapy would be important in breast cancer. Thus, considering our previous results, it is not only immunosuppressive cells like Tregs and MDSCs that might have to be targeted but it is also important to consider the specific cytokines produced by the CD4+ and CD8+ T-cell that are reactive to, in this case, Her-2. This study may also provide some mechanistic insights for a better understanding of the immune system in elderly and younger breast cancer patients. In any event, the findings that elderly breast cancer patients are not immunosenescent according to the assays conducted in this work augur well for the efficacy of immunomodulatory antibodies even in older patients.

\section{Methods}

\section{Patients}

The study included 40 elderly and 35 younger patients with breast cancer (Additional file 3: Figure S1). Blood samples from patients with different TNM stage were collected between March and November 2009, at the University Hospital Tuebingen. Blood was drawn prior to any treatment or surgery. Standard Ficoll-Hypaque gradient centrifugation was used to isolate the peripheral blood mononuclear cells (PBMCs) before they were cryopreserved for experimental purposes. The study was approved by the Institutional Ethics Committee of University Hospital Tuebingen (71/2009BO2) and a waiver of informed consent was granted for this study.

\section{Detection of tumour-associated antigen-reactiveT-cells}

To assess T-cell reactivity to Her-2, a 12-day in vitro culture was performed as described previously [21]. First, after thawing carefully, washing extensively, and assessing viability, PBMCs $\left(1 \times 10^{6}\right)$ were cultured in X-Vivo 15 defined medium (Lonza) supplemented with IL-4 (5 ng/ml: Sandoz, Basel, Switzerland) and IL-7 (5 ng/ml: Sterling-Winthrop, US), on day 0. On day 1, the PBMCs were stimulated with mixtures of Her-2 15-mer overlapping peptides (with an overlap of 11 amino acids) (PepMix, JPT Technologies, Berlin, Germany) at a concentration of $1 \mu \mathrm{g} / \mathrm{ml}$. The cells were supplemented with IL-2 (40U/ml: Chiron Behring GmbH, Marburg, Germany) on day3. On day12, after harvesting and washing, the cultured T-cells were restimulated (0.4-0.5 x $10^{6}$ cells/well) with Her-2 PepMix at a concentration of $1 \mu \mathrm{g} / \mathrm{ml}$ or left unstimulated as a negative control for 12 hours. Golgi-plug (BD Biosciences) was added at $1 \mu \mathrm{l} / \mathrm{ml}$ to all cultures. Patients' cells were stimulated with influenza nucleoprotein (NP) and membrane protein (M1) peptides as a positive control, as all subjects have been exposed to influenza during their lives and all 
possess $\mathrm{T}$ cells responsive to these peptides. After harvesting and washing, the cells were incubated with Gamunex (Talecris) to block Fc receptors, and with ethidium monoazide (EMA,MoBiTec GmbH, Goettingen, Germany), a marker for dead cells. Intracellular cytokine staining was performed after fixing and permeabilizing the cells with Cytofix/Cytoperm (BD Biosciences). Cells were simultaneously stained with CD3-PO (Invitrogen), CD4-Pacific Blue, TNF-FITC, IL-2-Alexa Fluor-700, IL-5-PE (Bio Legend), CD8-APC-Cy7, IFN- $\gamma$-PE-Cy7 (BD Biosciences), IL10-APC (Miltenyi Biotech) and IL-17-PerCP-Cy5.5 (eBioscience). Following the staining, cells were measured on a BD-LSR-II flow cytometer using the FACSDiva software (BD-Biosciences).

\section{Flow cytometry data analysis}

Data were analyzed using Flowjo software (Tree Star Inc.) as shown earlier [21]. To detect cytokine-producing cells, the stimulated samples were compared with unstimulated (negative) control and the response was considered positive when at least one cytokine was produced by the stimulated sample (representative FACS plot shown in Additional file 1: Table S2), defined as an at least two-fold increase in the peptide-stimulated culture compared to the unstimulated negative control, as established in earlier studies [19, 21].

\section{Statistical analysis}

Chi-square testing was performed to compare independent groups and Kaplan-Meier analysis was performed (Log-rank test and Gehan-Breslow test) for the survival estimates. Graph Pad Prism 6 was used to perform this analysis. A value of $p<0.05$ was considered statistically significant.

\section{Additional files}

Additional file 1: Table S2. Kaplan-Meier analysis of clinico-pathological parameters in older patients. (DOCX $17 \mathrm{~kb}$ )

Additional file 2: Table S1. Clinico-pathological characteristics of younger and older patients. (DOCX $15 \mathrm{~kb}$ )

Additional file 3: Figure S1. CD8+ and CD4+ T-cell response to Her-2: A representative plot of control and Her-2-stimulated cytokine (eg.TNF-producing CD8+ T-cells and CD4+ T-cells). (PPTX 89 kb)

\section{Abbreviations}

Her-2: Human epidermal growth factor receptor-2; IL: Interleukin; CTLA-4: Cytotoxic T-lymphocyte associated protein-4; PD-1:

Programmed cell death protein-1; PDL-1: Programmed death ligand-1.

\section{Competing interests}

The authors declare that they have no competing interests.

\section{Authors' contributions}

JKB planned and coordinated the project, performed assays, analyzed, interpreted data, and wrote the manuscript. BG collected the samples, obtained clinicopathological data, wrote and edited the manuscript. ED planned and coordinated the project, wrote and edited the manuscript. GP planned and coordinated the project, interpreted data, wrote and edited the manuscript. All authors read and approved the final version of the manuscript.

\section{Acknowledgements}

This project was supported by the European Commission (FP7 259679 "IDEAL") and the Bundesministerium für Bildung und Forschung (ISPE-BREAST, FKZ 01El1401).

\section{Author details}

'Department of Internal Medicine II, Centre for Medical Research, University of Tuebingen, Waldhoernlestr 22, 72072 Tuebingen, Germany. ${ }^{2}$ Radiology Clinic, Diagnostic and Interventional Radiology, University Hospital Tuebingen, Tuebingen, Germany. ${ }^{3}$ Present Address: BioNTech AG, Mainz, Germany. ${ }^{4}$ School of Science and Technology, College of Arts and Science, Nottingham Trent University, Nottingham, UK. ${ }^{5}$ Present Address: Yale Cancer Center, Yale University School of Medicine, New Haven, CT, USA.

Received: 7 June 2015 Accepted: 28 August 2015

Published online: 20 October 2015

\section{References}

1. Fulop T, Larbi A, Witkowski JM, Kotb R, Hirokawa K, Pawelec G. Immunosenescence and cancer. Crit Rev Oncog. 2013;18(6):489-513.

2. Du XL, Osborne C, Goodwin JS. Population-based assessment of hospitalizations for toxicity from chemotherapy in older women with breast cancer. J Clin Oncol. 2002;20(24):4636-42.

3. Pallis AG, Hatse S, Brouwers B, Pawelec G, Falandry C, Wedding U, et al. Evaluating the physiological reserves of older patients with cancer: the value of potential biomarkers of aging? J Geriatr Oncol. 2014;5(2):204-18. doi:10.1016/j.jgo.2013.09.001.

4. Aapro M, Wildiers $H$. Triple-negative breast cancer in the older population. Ann Oncol. 2012;23 Suppl 6:vi52-5. doi:10.1093/annonc/mds189.

5. Wildiers H. Adjuvant chemotherapy in older breast cancer patients: how to decide. J Geriatr Oncol. 2014;5 Suppl 1:S3. doi:10.1016/j.jgo.2014.06.011.

6. Wildiers $\mathrm{H}$, Brain E. Different adjuvant chemotherapy regimens in older breast cancer patients? Ann Oncol. 2015;26(4):613-5. doi: 10.1093/annonc/mdv015.

7. Desai S, Landay A. Early immune senescence in HIV disease. Curr HIV/AIDS Rep. 2010;7(1):4-10. doi: 10.1007/s11904-009-0038-4.

8. Pawelec G, Derhovanessian E, Larbi A. Immunosenescence and cancer. Crit Rev Oncol Hematol. 2010;75(2):165-72. doi: 10.1016/j.critrevonc.2010.06.012

9. Fulop T, Larbi A, Hirokawa K, Mocchegiani E, Lesourds B, Castle S, et al. Immunosupportive therapies in aging. Clin Interv Aging. 2007;2(1):33-54.

10. Larbi A, Franceschi C, Mazzatti D, Solana R, Wikby A, Pawelec G. Aging of the immune system as a prognostic factor for human longevity. Physiology (Bethesda). 2008;23:64-74. doi: 10.1152/physiol.00040.2007.

11. Fagnoni FF, Vescovini R, Passeri G, Bologna G, Pedrazzoni M, Lavagetto G, et al. Shortage of circulating naive CD8(+) T cells provides new insights on immunodeficiency in aging. Blood. 2000;95(9):2860-8.

12. Morel Y, Truneh A, Sweet RW, Olive D, Costello RT. The TNF superfamily members LIGHT and CD154 (CD40 ligand) costimulate induction of dendritic cell maturation and elicit specific CTL activity. J Immunol. 2001;167(5):2479-86.

13. Sharma S, Dominguez AL, Lustgarten J. Aging affect the anti-tumor potential of dendritic cell vaccination, but it can be overcome by co-stimulation with anti-OX40 or anti-4-1BB. Exp Gerontol. 2006;41(1):78-84. doi: 10.1016/ j.exger.2005.10.002.

14. Huang $H$, Patel DD, Manton KG. The immune system in aging: roles of cytokines, T cells and NK cells. Front Biosci. 2005;10:192-215.

15. Pawelec G, Lustgarten J, Ruby C, Gravekamp C. Impact of aging on cancer immunity and immunotherapy. Cancer Immunol Immunother. 2009;58(12):1907-8.

16. Malas S, Harrasser M, Lacy KE, Karagiannis SN. Antibody therapies for melanoma: New and emerging opportunities to activate immunity (Review). Oncol Rep. 2014;32(3):875-86. doi: 10.3892/or.2014.3275.

17. Page DB, Postow MA, Callahan MK, Wolchok JD. Checkpoint modulation in melanoma: an update on ipilimumab and future directions. Curr Oncol Rep. 2013;15(5):500-8. doi: 10.1007/s11912-013-0337-1.

18. Topalian SL, Hodi FS, Brahmer JR, Gettinger SN, Smith DC, McDermott DF, et al. Safety, activity, and immune correlates of anti-PD-1 antibody in cancer. N Engl J Med. 2012;366(26):2443-54. doi: 10.1056/NEJMoa1200690.

19. Weide B, Zelba H, Derhovanessian E, Pflugfelder A, Eigentler TK, Di Giacomo AM, et al. Functional T cells targeting NY-ESO-1 or Melan-A are predictive 
for survival of patients with distant melanoma metastasis. J Clin Oncol. 2012;30(15):1835-41. doi: 10.1200/JCO.2011.40.2271.

20. Zelba H, Weide B, Martens A, Derhovanessian E, Bailur JK, Kyzirakos C, et al. Circulating CD4+ T cells that produce IL4 or IL17 when stimulated by melan-A but not by NY-ESO-1 have negative impacts on survival of patients with stage IV melanoma. Clin Cancer Res. 2014;20(16):4390-9. doi: 10.1158/ 1078-0432.CCR-14-1015.

21. Bailur JK, Gueckel B, Derhovanessian E, Pawelec G. Presence of circulating Her2-reactive CD8 + T-cells is associated with lower frequencies of myeloid-derived suppressor cells and regulatory $T$ cells, and better survival in older breast cancer patients. Breast Cancer Res. 2015;17:34. doi: 10.1186/s13058-015-0541-z.

22. Bonertz A, Weitz J, Pietsch DH, Rahbari NN, Schlude C, Ge Y, et al. Antigen-specific Tregs control T cell responses against a limited repertoire of tumor antigens in patients with colorectal carcinoma. Clin Invest. 2009;119(11):3311-21. doi: 10.1172/JCl39608.

23. Vence L, Palucka AK, Fay JW, Ito T, Liu YJ, Banchereau J, et al. Circulating tumor antigen-specific regulatory $T$ cells in patients with metastatic melanoma. Proc Natl Acad Sci U S A. 2007;104(52):20884-9. doi: 10.1073/ pnas. 0710557105 .

24. Chen WC, Lai YH, Chen HY, Guo HR, Su IJ, Chen HH. Interleukin-17-producing cell infiltration in the breast cancer tumour microenvironment is a poor prognostic factor. Histopathology. 2013;63(2):225-33. doi: 10.1111/his.12156.

25. Zaynagetdinov R, Sherrill TP, Gleaves LA, McLoed AG, Saxon JA, Habermann $A C$, et al. Interleukin-5 facilitates lung metastasis by modulating the immune microenvironment. Cancer Res. 2015;75(8):1624-34. doi: 10.1158/ 0008-5472.CAN-14-2379.

26. Simson L, Ellyard Jl, Dent LA, Matthaei Kl, Rothenberg ME, Foster PS, et al. Regulation of carcinogenesis by IL-5 and CCL11: a potential role for eosinophils in tumor immune surveillance. J Immunol. 2007;178(7):4222-9.

27. Derhovanessian E, Adams V, Hahnel K, Groeger A, Pandha H, Ward S, et al. Pretreatment frequency of circulating IL-17+ CD4+ T-cells, but not Tregs, correlates with clinical response to whole-cell vaccination in prostate cancer patients. Int J Cancer. 2009;125(6):1372-9. doi: 10.1002/ijc.24497.

28. Middleton GW, Annels NE, Pandha HS. Are we ready to start studies of Th17 cell manipulation as a therapy for cancer? Cancer Immunol Immunother. 2012;61(1):1-7. doi: 10.1007/s00262-011-1151-y.

29. Benevides L, Cardoso CR, Tiezzi DG, Marana HR, Andrade JM, Silva JS. Enrichment of regulatory $T$ cells in invasive breast tumor correlates with the upregulation of IL-17A expression and invasiveness of the tumor. Eur J Immunol. 2013;43(6):1518-28. doi: 10.1002/eji.201242951.

30. Chatterjee S, Das S, Chakraborty P, Manna A, Chatterjee M, Choudhuri SK. Myeloid derived suppressor cells (MDSCs) can induce the generation of Th17 response from naive CD4+ T cells. Immunobiology. 2013;218(5):718-24. doi: 10.1016/j.imbio.2012.08.271

31. Fujisawa T, Joshi BH, Puri RK. IL-13 regulates cancer invasion and metastasis through IL-13Ralpha2 via ERK/AP-1 pathway in mouse model of human ovarian cancer. Int J Cancer. 2012;131(2):344-56. doi: 10.1002/ijc.26366.

32. Goldstein R, Hanley C, Morris J, Cahill D, Chandra A, Harper P, et al. Clinical investigation of the role of interleukin-4 and interleukin-13 in the evolution of prostate cancer. Cancers (Basel). 2011;3(4):4281-93. doi: 10.3390/cancers3044281.

33. Roca H, Craig MJ, Ying C, Varsos ZS, Czarnieski P, Alva AS, et al. IL-4 induces proliferation in prostate cancer PC3 cells under nutrient-depletion stress through the activation of the JNK-pathway and survivin up-regulation. J Cell Biochem. 2012;113(5):1569-80. doi: 10.1002/jcb.24025

34. Voronov E, Shouval DS, Krelin Y, Cagnano E, Benharroch D, Iwakura Y, et al. IL-1 is required for tumor invasiveness and angiogenesis. Proc Natl Acad Sci U S A. 2003;100(5):2645-50. doi: 10.1073/pnas.0437939100.

35. Salgado R, Junius S, Benoy I, Van Dam P, Vermeulen P, Van Marck E, et al. Circulating interleukin-6 predicts survival in patients with metastatic breast cancer. Int J Cancer. 2003;103(5):642-6. doi: 10.1002/ijc.10833.

36. Ikeda $\mathrm{H}$, Old LJ, Schreiber RD. The roles of IFN gamma in protection against tumor development and cancer immunoediting. Cytokine Growth Factor Rev. 2002;13(2):95-109.

37. Rosenberg SA, Lotze MT, Muul LM, Chang AE, Avis FP, Leitman S, et al. A progress report on the treatment of 157 patients with advanced cancer using lymphokine-activated killer cells and interleukin-2 or high-dose interleukin-2 alone. N Engl J Med. 1987;316(15):889-97. doi: 10.1056/NEJM198704093161501.

38. Kaplan DH, Shankaran V, Dighe AS, Stockert E, Aguet M, Old LJ, et al. Demonstration of an interferon gamma-dependent tumor surveillance system in immunocompetent mice. Proc Natl Acad Sci U S A. 1998;95(13):7556-61.
39. Street SE, Cretney E, Smyth MJ. Perforin and interferon-gamma activities independently control tumor initiation, growth, and metastasis. Blood. 2001;97(1):192-7.

40. Vadhan-Raj S, Al-Katib A, Bhalla R, Pelus L, Nathan CF, Sherwin SA, et al. Phase I trial of recombinant interferon gamma in cancer patients. J Clin Oncol. 1986:4(2):137-46.

41. Windbichler $\mathrm{GH}$, Hausmaninger $H$, Stummvoll W, Graf AH, Kainz C, Lahodny J, et al. Interferon-gamma in the first-line therapy of ovarian cancer: a randomized phase III trial. Br J Cancer. 2000;82(6):1138-44. doi: 10.1054/ bjoc.1999.1053.

42. van Horssen R, Ten Hagen TL, Eggermont AM. TNF-alpha in cancer treatment: molecular insights, antitumor effects, and clinical utility. Oncologist. 2006;11(4):397-408. doi: 10.1634/theoncologist.11-4-397.

\section{Submit your next manuscript to BioMed Central and take full advantage of:}

- Convenient online submission

- Thorough peer review

- No space constraints or color figure charges

- Immediate publication on acceptance

- Inclusion in PubMed, CAS, Scopus and Google Scholar

- Research which is freely available for redistribution 